\title{
Commentary
}

\section{The Past, Present, and Future of Ego Depletion}

\author{
Michael Inzlicht ${ }^{1}$ and Malte Friese ${ }^{2}$ \\ 1 Department of Psychology, University of Toronto, ON, Canada \\ 2 Department of Psychology, Saarland University, Saarbrücken, Germany
}

\begin{abstract}
At the center of social psychology just a few years ago, ego depletion is now widely seen as a controversial topic, one of the chief victims of the replication crisis. Despite over 600 studies of apparent support, many are now asking if ego depletion is even real. Here, we comment on the articles included in this Special Issue: Ego Depletion and Self-Control: Conceptual and Empirical Advances. Specifically, we delineate the contributions and limitations of these articles by embedding them in a brief history of ego depletion, describing the current state of uncertainty about ego depletion's scientific status, and outlining necessary steps for the study of ego depletion to have a healthy future. To us, the most troubling aspect of this controversy is not what it suggests about ego depletion, but what it suggests about social psychology more broadly. If the mere existence of ego depletion is seriously doubted by many, what can be confidently regarded as real in social psychology? By increasing the precision of our theories, continuously validating our manipulations and measures, and practicing the full suite of open science practices, we have the potential to identify legitimate and robust effects and build a cumulative and trustworthy psychological science.
\end{abstract}

Is ego depletion real? This question seems absurd. Of course, it is real! About 600 studies have confirmed the veracity of this most celebrated of findings (Cunningham \& Baumeister, 2016). Yet, as absurd as it might seem, this is the question lurking behind each of the seven papers included in this special issue of Social Psychology. At the very center of social psychology just a few years ago, ego depletion has quickly found itself on the outs. Deserved or not, the topic of ego depletion is now widely seen as too controversial for most, one of the chief victims of the replication crisis (Friese, Loschelder, Gieseler, Frankenbach, \& Inzlicht, 2019).

Numerous social psychologists who were once active researchers of ego depletion have abandoned the topic, but not the authors of this Special Issue: Ego Depletion. The authors have done the hard work of setting right the good ship ego depletion. Some authors have started the long and hard task of establishing the construct validity of basic laboratory tasks (Wimmer, Dome, Hancock, \& Wennekers, 2019), some have developed high-powered designs to probe the basic depletion effect (Wenzel, Lind, Rowland, Zahn, \& Kubiak, 2019), and others have provided critical tests of long-held assertions (Finley, Tang, \& Schmeichel, 2019). In doing so, these authors have made important contributions to the highly contested field of ego depletion. Yet, other authors propose that there is no future for ego depletion (Vadillo, 2019), that ego depletion is sinking, and that the best course of action is to abandon the ship.

Some observers appear content to look away from the controversy, construing it as a problem specific to ego depletion and having little bearing on their own cherished topics. In this view, the problems of ego depletion are encapsulated, fenced off, with few lessons for other areas. To us, however, the most troubling aspect of this controversy is not what it suggests about ego depletion, but what it suggests about social psychology more broadly. If the mere existence of ego depletion, with its $600+$ studies of apparent support, is seriously doubted by many, what can be confidently regarded as real in social psychology (Baumeister, 2019)? What other topics that appear true and real, that have amassed a mountain of apparent support (e.g., Border et al., 2019), will be disbelieved next? The true lessons reach much farther than ego depletion, perhaps indicting considerable parts of our discipline. Before contemplating these unnerving possibilities, we offer a summary of how things changed so rapidly for research on ego depletion. 


\section{A Brief History of Ego Depletion}

The story of ego depletion contains four principal chapters, the contents of which are still being written, including by authors of the current Special Issue: Ego Depletion and SelfControl: Conceptual and Empirical Advances.

\section{Ego Depletion Captivates Social Psychology}

In 1994, Roy Baumeister and his colleagues (Baumeister, Heatherton, \& Tice, 1994) proposed the resource model of self-control (see Gieseler, Loschelder, \& Friese, 2019), with the first empirical confirmations of it coming a few years later (Baumeister, Bratslavsky, Muraven, \& Tice, 1998; Muraven, Tice, \& Baumeister, 1998). The resource model proposed that self-control is a central, yet limited resource. Self-control is thought to be central in the sense that it underlies a vast array of behaviors that appear different, yet that involve the inhibition of some pressing urge or impulse. Self-control fuels one's capacity to eat broccoli over chocolate or stay calm while experiencing emotional duress. Self-control is thought to be limited in the sense that it relies on a resource that runs out after use, a sort of mental fuel. Engaging self-control consumes and partially depletes this limited inner resource, leaving one in a state of ego depletion that leaves further efforts at self-control prone to failure (Baumeister, 2014; Baumeister, Vohs, \& Tice, 2007). The resource model further proposed that in the long run, engaging in self-control would have a training effect and build up self-control strength, just like a physical muscle that is getting stronger with regular exercise (Baumeister \& Vohs, 2016b; cf. Friese, Frankenbach, Job, \& Loschelder, 2017).

The notion that self-control is central, that it underlies a far range of different behaviors, is what made ego depletion special. It is the broad applicability of ego depletion that captivated social psychology for two decades. Hundreds of studies were soon being published implicating ego depletion in all matter of outcomes: eating, drinking alcohol, exercise, aggression, test performance, smoking, drug use, cheating, empathy, racism, marital infidelity, to name just a few (see Baumeister \& Tierney, 2011, for a review). Soon after, ego depletion left the social psychology laboratory to have an impact in health, medical, and educational contexts (Dai, Milkman, Hofmann, \& Staats, 2014; Persson, Barrafrem, Meunier, \& Tinghög, 2019; Sievertsen, Gino, \& Piovesan, 2016). This was a truly exciting time because it appeared like a simple principle could help us make sense of a vast array of behaviors in numerous life domains not only in humans, but even in other animals (e.g., Miller, Pattison, DeWall, Rayburn-Reeves, \& Zentall, 2010). And this excitement was shared by many in and out of the field, including by the former President Barack Obama (Lewis, 2012).

Despite its existential controversy, we submit that exciting work is still being conducted, including work that does not focus on self-control performance, but on other outcomes that may be affected by the exertion of effort. In this special issue, for example, we learned that selfcontrol and effortful exertion are visible to others (Furley, Kohlhaas, Englert, Nieuwenhuys, \& Bertrams, 2019). That is, perceivers can accurately determine whether someone did or did not exert effort on a previous task from thin slices of nonverbal, facial expressions. We also learned that working on an effortful task may affect subsequent pupil dilation while viewing rewarding stimuli, possibly indicating differential reward sensitivity (Giacomantonio, Jordan, \& Fennis, 2019). Under other circumstances, effort might affect subsequent ratings of pain (Silvestrini, Vuignier, Matthey, \& Piguet, 2019).

\section{Is Self-Control Really a Limited Resource?}

Despite the immense appeal of the phenomenon of ego depletion, the process via which depletion came about became a topic of much debate (Inzlicht \& Berkman, 2015). That is, scholars started asking why exerting self-control on one task impacted self-control on a subsequent task, increasingly finding the resource model wanting. The resource model, at least in its original form, suggested that initial bouts of self-control deplete and drain the mental fuel needed to power the will. Yet questions and inconsistencies started appearing.

First, if self-control is powered by some limited resource, what precisely is this resource? One influential account suggested that the resource is more than a metaphor and that its identity is blood glucose (Gailliot et al., 2007). Despite its intuitive appeal, however, this notion never stood up to scrutiny (Kurzban, 2010). And, in this special issue, we have perhaps the most rigorous test (and failure) of the glucose hypothesis that may put this notion to rest for good (Finley et al., 2019; see also, Dang, 2016b; Vadillo, Gold, \& Osman, 2016, for reviews).

Second, if depletion is about some incapacity - if people are unable to control themselves because of resource unavailability - it is difficult to understand how small motivational incentives could reverse depletion instantly. Studies started showing that even when people worked hard on a previous task, supposedly in a state of ego depletion, they could perform just fine on a subsequent task if they were sufficiently motivated. For example, paying participants, telling them the research was for a good cause, or simply being kind to them was sufficient to ease the depletion effect (Luethi et al., 2016; Muraven, Gagné, \& Rosman, 2008; Muraven \& Slessareva, 2003). Numerous such 
studies started appearing (see Loschelder \& Friese, 2016; Masicampo, Martin, \& Anderson, 2014, for reviews), making it clear that the resource model was insufficient and in need of amendment. In the current special issue, we see at least two papers that highlight problems with the original resource model, both of which question the idea that self-control failure is the product of some mental fuel that is no longer available (Giacomantonio et al., 2019; Silvestrini et al., 2019).

In response to these theoretical deficiencies, a number of scholars started proposing alternative accounts of the ego depletion effect (Inzlicht \& Schmeichel, 2012; Inzlicht, Schmeichel, \& Macrae, 2014; Kool \& Botvinick, 2014; Kurzban, Duckworth, Kable, \& Myers, 2013). While the alternative accounts are far from identical, they each place motivation at the center. Initial bouts of effortful control, according to these accounts, do not diminish people's ability to exert subsequent effort, but diminish people's willingness to exert effort. People fail to control themselves sufficiently because they choose not to, perhaps because they find alternative courses of action more rewarding. These motivational accounts are not without their own critiques (Baumeister \& Vohs, 2016b). Nonetheless, they were sufficient to compel a revision of the original resource model (Baumeister, 2014) that arguably makes it difficult to distinguish from motivational accounts at the proximate level of analysis (Inzlicht \& Berkman, 2015; Inzlicht \& Schmeichel, 2016).

\section{Is Ego Depletion Real?}

Despite the excitement with which these alternative accounts were greeted (at least by some scholars), their generativity was short lived because it soon became clear that they were alternative explanations for a phenomenon whose very existence was increasingly doubted. Instead of scrutinizing new theoretical models trying to explain the origins of ego depletion effects, the field took a step backward (read: forward) to re-assess the basics. The first sign that something was not right with the ego depletion literature was a series of bias-corrected analyses suggesting that the overall ego depletion effect was, at best, a lot smaller than previously thought or, at worst, not significantly different from zero (Carter, Kofler, Forster, \& McCullough, 2015; Carter \& McCullough, 2014). This contrasted sharply with an early meta-analysis suggesting that the overall ego depletion effect was not only robust, but large in size by today's standards (Hagger, Wood, Stiff, \& Chatzisarantis, 2010), about $50 \%$ larger than the average effect in social psychology (Richard, Bond, \& Stokes-Zoota, 2003). One problem with this early meta-analysis was that it did not include even a single unpublished study, nor did it attempt to correct for so-called small-study effects that may contribute to an overestimation of meta-analytic effect size estimates. This early analysis, that is, failed to correct for serious threats to the validity of any meta-analysis: publication bias and imprecise small studies.

Although not without their own controversy (Inzlicht, Gervais, \& Berkman, 2015), there now exist multiple methods to correct for these biases (Carter, Schönbrodt, Gervais, \& Hilgard, 2019). And when a series of these bias-correction techniques were applied (Carter et al., 2015; Carter \& McCullough, 2014), some of them made the ego depletion effect appear small, possibly nonexistent. To be sure, each of these methods is imperfect and should not necessarily be trusted when looked at in isolation, but when several of these methods converged on the notion that bias is a serious concern in the ego depletion literature, it became clear that uncorrected meta-analytic effect size estimates were likely considerably off the mark.

Pointing out deficiencies of these bias-corrected metaanalyses, numerous scholars pushed back on their conclusions (Cunningham \& Baumeister, 2016; Inzlicht et al., 2015), suggesting that a more definitive evaluation could be reached by preregistered, high-powered replications (Inzlicht \& Berkman, 2015). While a few failed replications of the classic ego depletion effect started appearing in the literature shortly thereafter (Xu et al., 2014), some even preregistered (Lurquin et al., 2016) scholars only started to change their minds en masse after a widely publicized registered replication report failed to find any evidence of ego depletion (Hagger et al., 2016). This report involved 23 laboratories worldwide collectively testing over 2,000 participants. Of note, when the participating laboratories were polled in advance, 22 out of 23 of them (some of whom were experts in self-control) predicted that they would successfully replicate the depletion effect.

To be fair, it is difficult to say how valid a test this multisite replication of one specific ego depletion study really was. Several scholars raised doubts and criticized various aspects of the study and the process that led to it (Baumeister, 2019; Baumeister \& Vohs, 2016a; Dang, 2016a). Nevertheless, that this highly powered study returned no evidence of ego depletion was a real blow, the effects of which we are still grappling with today. Indeed, a critical analysis of the various arguments in favor of or against the reality of ego depletion suggested that despite $600+$ studies appearing to demonstrate ego depletion, the available evidence was inconclusive (Friese et al., 2019). This uncertainty is evident in this Special Issue: Ego Depletion and Self-Control: Conceptual and Empirical Advances as well. Four studies with relatively large sample sizes (average $N$ per cell $=131.71$ ) found no evidence of depletion (Finley et al., 2019; Wenzel, Lind, et al., 2019; Wimmer et al., 2019); another four studies with considerably lower sample sizes (average $N$ per cell $=38.25$ ) found at least weak support (Furley et al., 2019; Giacomantonio et al., 2019; 
Silvestrini et al., 2019). Of note, this special issue includes a paper suggesting that considering the ego depletion literature as a whole the more recent the studies, the smaller the depletion effect, with a distinct possibility of depletion disappearing as a topic that reveals effect sizes in the expected direction by the year 2020 (Vadillo, 2019).

\section{Starting Over}

Despite the feeling of desperation some of us are today feeling, there are reasons to not completely abandon the topic. First, despite some assertions to the contrary (Vohs, Glass, Maddox, \& Markman, 2010), ego depletion can be construed as a form of mental fatigue (Baumeister, 2019; Inzlicht \& Berkman, 2015), which has long been known to have downstream consequences on thoughts and behaviors (Hockey, 2013). All of us have experienced feeling tired, of not having enough energy to continue working, and when these feelings accrue, we typically have the desire to stop exerting effort. In fact, lay people we speak to sometimes wonder if this seemingly trivial notion is really worthy of the extensive study: "Do we really need scientific research to find out whether people feel less inclined to do effortful stuff when feeling drained? Of course people do!" Indeed, there is evidence that depletion/fatigue affects outcomes in real life, including medical decisions and medical compliance among health-care workers (Allan et al., 2019; Dai et al., 2014), though these real-world effects are sometimes contradictory (Allan et al., 2019; Randles, Harlow, \& Inzlicht, 2017; Wenzel, Rowland, Zahn, \& Kubiak, 2019). Yet, it is unclear to what extent this real-life phenomenology is reflected in typical ego depletion studies in the laboratory.

If depletion is nothing but a form of mental fatigue, then certainly we should be able to find evidence of it in laboratory settings. Generating this evidence, however, might require radically different approaches and laboratory paradigms. In some ways, the next chapter of research on ego depletion has started over, rethinking not only the concept of ego depletion (Lurquin \& Miyake, 2017), but also how to experimentally evoke it in the laboratory and measure it in the field.

Conceptual and empirical work has suggested that not only is depletion akin to fatigue, it might also have a family resemblance to boredom (Milyavskaya, Inzlicht, Johnson, \& Larson, 2018; Westgate \& Wilson, 2018). Scholars have also started to systematically experiment with the ego depletion paradigm, including in this special issue. For example, whereas typical depletion paradigms evoke depletion with only a few minutes of mental effort, startling work has suggested that multiple hours might be needed for depletion/fatigue to truly set in (Blain, Hollard, \& Pessiglione, 2016). Whereas typical depletion paradigms have used between-subject designs, newer approaches have experimented with within-subject or so-called crossover designs (Francis, Milyavskaya, Lin, \& Inzlicht, 2018; Lin, Saunders, Friese, \& Inzlicht, 2019; Wenzel, Lind, et al., 2019).

Most heartening, scholars are starting the long and ongoing process of validating experimental procedures to determine whether they are even capable of evoking depletion effects and whether such evocations follow a dose-response relationship (Wimmer et al., 2019). Importantly, similar construct validation work is needed for dependent variables. There is a host of different self-control-related dependent variables that only share a small common core (Duckworth \& Kern, 2011; Saunders, Milyavskaya, Etz, Randles, \& Inzlicht, 2018). Likely, not all of them will be equally suitable to assess ego depletion effects, many of them may need to be tailored to the specific population a study is conducted in (Baumeister, 2019). Further, there may be specific combinations of independent and dependent variables that more reliably produce ego depletion effects than the same dependent variable, but with a different independent variable (Gieseler et al., 2019). Although such systematic attempts at construct validation should have occurred at the outset of this program of research two decades ago (beyond the occasional unreported pretests in some laboratories; Baumeister, 2019), it is not too late to start now. Indeed, the very survival of ego depletion as a legitimate scientific concept might rely on such attempts.

\section{Recommendations for Future Research on Ego Depletion}

As heartening as these initial steps are, the field still has a ways to go before it regains scientific respectability. Following other prescriptions (Friese et al., 2019), including insightful ones in this special issue (Wenzel, Lind, et al., 2019, Table 3), we offer a set of recommendations for future research on ego depletion, if not for social psychology more generally.

First, we advise scholars to increase the precision of theory to escape what some call the conceptual crisis of ego depletion (Lurquin \& Miyake, 2017). A major step in such clarification is to establish construct validity for the various independent and dependent variables used in ego depletion research (e.g., Arber et al., 2017). For example, though it is widely used to evoke depletion, the letter-cancelation task has never been validated as an appropriate tool for such ends. Unfortunately, in this special issue, we learn that this task failed basic tests of validation and as such might not be a suitable inducer of ego depletion (Wimmer et al., 2019). We wonder how other commonly used manipulations will fare when their validity is scrutinized. 
A related step is to offer clear operational definitions of self-control itself so that we can assess the extent to which independent and dependent variables tap the construct (Lurquin \& Miyake, 2017). Most critical, though, is to derive more well specified models that make unambiguous, falsifiable predictions (Gieseler et al., 2019). For example, both updates (Baumeister \& Vohs, 2016b; Evans, Boggero, \& Segerstrom, 2016) and alternatives to the resource model (Inzlicht et al., 2014; Kurzban et al., 2013) suggest motivation plays a critical role (as moderator for the former and mediation for the latter). However, neither account specifies when people become unwilling to exert further effort, making it difficult to predict when one should observe an ego depletion effect or not (Lurquin \& Miyake, 2017). Such specification is needed to move forward.

Second, we recommend a moratorium on non-preregistered empirical studies of ego depletion. Going forward, that is, we suggest that all empirical investigations of ego depletion be preregistered. We note, with some lament, that not a single paper in this Special Issue: Ego Depletion and SelfControl: Conceptual and Empirical Advances included a preregistered study. Such preregistration is important because it acts as a barrier against (even inadvertent) use of questionable research practices (Simmons, Nelson, \& Simonsohn, 2011) that inflate both the rate of false positives and effect sizes, effect sizes and lower the trustworthiness of findings. In a field that has suffered such reputational damage, increasing trust is paramount.

Third, we recommend that future empirical investigations practice the full range of open science practices, which include not only preregistration, but also posting of open data and materials and running high-powered studies. Many of the studies in this special issue used high-powered designs (e.g., Finley et al., 2019; Wenzel, Lind, et al., 2019), and all of the papers posted open data and open materials.

Related, given how badly publication bias has warped the field of ego depletion (Friese et al., 2019), future papers need a full accounting of their file drawers. Publication bias is as severe a threat to the research literature as the use of questionable research practices. The most tangible consequence of questionable research practices is a sharp increase in false positives that may give the impression of a reliable effect when in fact there is little to see. This may motivate other researchers to study the effect further and waste resources. The most tangible consequence of publication bias, by contrast, is the distortion of meta-analytic effect size estimates. Meta-analyses are regarded as particularly trustworthy sources of evidence; thus, biases in meta-analytic results may hamper scientific progress because incorrect theories and beliefs may remain popular (Friese \& Frankenbach, in press). Therefore, we need to know how many studies were conducted on any particular research question to calibrate the strength of evidence for any one claim. Going forward, we thus advise that papers report on every single study conducted on a specific research question (even the null results) and to explicitly state that they have reported on all studies. In some cases, internal meta-analyses of all studies conducted on a given research question may provide an informative summary of the evidence (Goh, Hall, \& Rosenthal, 2016).

Fourth, we recommend that scholars leave the laboratory to conduct field research in the real world. The popularity of ego depletion was due, in no small part, to how widely applicable the idea was in the real world. Despite this broad applicability, work on depletion has mostly been conducted in the sterile confines of the experimental laboratory. Instead, we recommend that scholars interrogate depletion in the wild (e.g., Baumeister, Wright, \& Carreon, 2019; Hofmann, Baumeister, Förster, \& Vohs, 2012; Milyavskaya \& Inzlicht, 2017; Wilkowski, Ferguson, Williamson, \& Lappi, 2018). More than that, we recommend that scholars conduct observational studies that examine depletion as it impacts important outcomes in the real world (Allan et al., 2019; Dai et al., 2014). Every paper in this special issue used an experimental laboratory approach; we hope to see more work bridging laboratory and field in the future.

\section{Ego Depletion as a Cautionary Tale}

This special issue of Social Psychology and our commentary of it have been about ego depletion. In many ways, however, the history we recounted and the recommendations we gave apply to social psychology more broadly. It would be a mistake, in our estimation, to think the problems we have outlined here are specific to ego depletion. Instead, we urge readers to look in the mirror and ask themselves if they see parallels between the unsettling story of ego depletion and their own cherished research topics. If researchers now wonder if a research topic with so much apparent support may in fact be a figment, we need to ask what other research areas might be similarly problematic.

Broad tests of the replicability of psychology suggest that the case of ego depletion might be less exception and more rule in social psychology, where a majority of papers have failed the replication test (Klein et al., 2018; Nosek \& Lakens, 2014; Open Science Collaboration, 2015). To be sure, replication projects have received their share of criticism and good points have been made. Nevertheless, it is beyond doubt to us that social psychology has a serious issue to grapple with. Indeed, we see uncomfortable similarities between the state of ego depletion and the state of numerous well-known and apparently well-supported research areas. For example, the phenomenon of stereotype threat (Spencer, Steele, 
\& Quinn, 1999; Steele \& Aronson, 1995) has so much apparent empirical support, and it long left the confines of the laboratory and has been applied to real school settings (Miyake et al., 2010). Yet, not only has stereotype threat failed a number of replication tests (Ganley et al., 2013; Pennington, Litchfield, McLatchie, \& Heim, 2019), some of these tests were preregistered in advance (Flore, Mulder, \& Wicherts, 2019). Most troubling, metaanalyses that accounted for publication bias and smallstudy effects suggest the effect of stereotype threat is a lot smaller than previously thought, possibly no different from zero (Flore \& Wicherts, 2015; Zigerell, 2017).

The area of so-called behavioral priming seemed similarly well-supported only a few years ago, with its methods ubiquitous in the field (Bargh, Chen, \& Burrows, 1996). But, now numerous registered replication failures (Doyen, Klein, Pichon, \& Cleeremans, 2012; Harris, Coburn, Rohrer, \& Pashler, 2013; O'Donnell et al., 2018) have made using such methods practically forbidden. Research on embodiment (Donnellan, Lucas, \& Cesario, 2015; Wagenmakers et al., 2016), money priming (Lodder, Ong, Grasman, \& Wicherts, 2019), candidate genes (Border et al., 2019), and mindset interventions (Glerum, Loyens, Wijnia, \& Rikers, 2019; Sisk, Burgoyne, Sun, Butler, \& Macnamara, 2018; but see, Yeager et al., 2019) have each suffered similarly.

Our point here is not to provide a comprehensive list of research areas that have suffered under the current regime of methodological (and also theoretical!) rigor. Instead, it is to suggest that many areas in social psychology may have fared poorly. While it is easy to point a finger of disparagement at ego depletion, it is wiser to reflect on how we may have collectively erred in too many research areas and to ask how we can lift our beleaguered topics onto more solid evidentiary footing. There is no alternative to regaining trust in the field more broadly. On the positive side, critical reconsiderations of cherished findings will allow the field to more confidently stand by the phenomena that are robust and trustworthy and that make a difference to people's lives. The recommendations we have for other areas are thus the same as for ego depletion: drafting more precise and falsifiable theory, establishing the construct validity of our experimental manipulations and dependent variables, practicing the full suite of open science practices, especially preregistration, accounting for the file drawer, and so on. Our hope is that in the future we can avoid some of the pitfalls that might have unnaturally propped up phenomena like ego depletion. As unsettling as the story of ego depletion is, we hope to learn from it and not repeat it.

\section{Conclusion}

This special issue of Social Psychology has allowed us to reflect on the tumultuous past of ego depletion and to ponder its possible future. The papers in this special issue have contributed to the study of ego depletion in various ways. These papers have described the phenomenon of self-control (Furley et al., 2019), tested alternatives to the resource model (Giacomantonio et al., 2019; Silvestrini et al., 2019), proposed new paradigms (Wenzel, Lind, et al., 2019), tested long-held assertions (Finley et al., 2019), and examined construct validity (Wimmer et al., 2019). Lurking behind each of these papers is the vexing question of whether ego depletion is even real. For a topic that has been studied for over two decades with 600+ studies of apparent support, this is an untenable situation (Friese et al., 2019).

We can do better. If ego depletion is to have a future and there are no guarantees (Vadillo, 2019) - scholars will need to start over and establish its empirical bona fides one step at a time.

\section{References}

Allan, J. L., Johnston, D. W., Powell, D. J. H., Farquharson, B., Jones, M. C., Leckie, G., \& Johnston, M. (2019). Clinical decisions and time since rest break: An analysis of decision fatigue in nurses. Health Psychology, 38, 318-324. https://doi. org/10.1037/hea0000725

Arber, M. M., Ireland, M. J., Feger, R., Marrington, J., Tehan, J., \& Tehan, G. (2017). Ego depletion in real-time: An examination of the sequential-task paradigm. Frontiers in Psychology, 8, 1672. https://doi.org/10.3389/fpsyg.2017.01672

Bargh, J. A., Chen, M., \& Burrows, L. (1996). Automaticity of social behavior: Direct effects of trait construct and stereotype activation on action. Journal of Personality and Social Psychology, 71, 230-244. https://doi.org/10.1037/0022-3514. 71.2 .230

Baumeister, R. F. (2014). Self-regulation, ego depletion, and inhibition. Neuropsychologia, 65, 313-319. https://doi.org/ 10.1016/j.neuropsychologia.2014.08.012

Baumeister, R. F. (2019). Self-control, ego depletion, and social psychology's replication crisis. In A. Mele (Ed.), Surrounding self-control. New York, NY: Oxford University Press. https://doi. org/10.31234/osf.io/uf3cn

Baumeister, R. F., Bratslavsky, E., Muraven, M., \& Tice, D. M. (1998). Ego depletion: Is the active self a limited resource? Journal of Personality and Social Psychology, 74, 1252-1265. https://doi.org/10.1037/0022-3514.74.5.1252

Baumeister, R. F., Heatherton, T. F., \& Tice, D. M. (1994). Losing control: How and why people fail at self-regulation. San Diego, CA: Academic Press.

Baumeister, R. F., \& Tierney, J. (2011). Willpower: Rediscovering the greatest human strength. New York, NY: Penguin Press. Retrieved from https://sivers.org/book/Willpower

Baumeister, R. F., \& Vohs, K. D. (2016a). Misguided effort with elusive implications. Perspectives on Psychological Science, 11, 574-575. https://doi.org/10.1177/1745691616652878

Baumeister, R. F., \& Vohs, K. D. (2016b). Strength model of selfregulation as limited resource: Assessment, controversies, update. In J. M. Olson \& M. P. Zanna (Eds.), Advances in experimental social psychology: Vol. 54. Advances in experimental social psychology (pp. 67-127). San Diego, CA: Elsevier Academic Press. https://doi.org/10.1016/bs.aesp.2016.04.001 
Baumeister, R. F., Vohs, K. D., \& Tice, D. M. (2007). The strength model of self-control. Current Directions in Psychological Science, 16, 351-355. https://doi.org/10.1111/j.1467-8721.2007.00534.x

Baumeister, R. F., Wright, B. R. E., \& Carreon, D. (2019). Selfcontrol "in the wild": Experience sampling study of trait and state self-regulation. Self and Identity, 18, 494-528. https:// doi.org/10.1080/15298868.2018.1478324

Blain, B., Hollard, G., \& Pessiglione, M. (2016). Neural mechanisms underlying the impact of daylong cognitive work on economic decisions. Proceedings of the National Academy of Sciences, 113, 6967-6972. https://doi.org/10.1073/pnas.1520527113

Border, R., Johnson, E. C., Evans, L. M., Smolen, A., Berley, N., Sullivan, P. F., \& Keller, M. C. (2019). No support for historical candidate gene or candidate gene-by-interaction hypotheses for major depression across multiple large samples. American Journal of Psychiatry, 176, 376-387. https://doi.org/10.1176/ appi.ajp. 2018.18070881

Carter, E. C., Kofler, L. M., Forster, D. E., \& McCullough, M. E. (2015). A series of meta-analytic tests of the depletion effect: Self-control does not seem to rely on a limited resource. Journal of Experimental Psychology: General, 144, 796-815. https://doi.org/10.1037/xge0000083

Carter, E. C., \& McCullough, M. E. (2014). Publication bias and the limited strength model of self-control: Has the evidence for ego depletion been overestimated? Frontiers in Psychology, 5, 1-11. https://doi.org/10.3389/fpsyg.2014.00823

Carter, E. C., Schönbrodt, F. D., Gervais, W. M., \& Hilgard, J. (2019). Correcting for bias in psychology: A comparison of meta-analytic methods. Advances in Methods and Practices in Psychological Science, 2, 115-144. https://doi.org/10.1177/ 2515245919847196

Cunningham, M. R., \& Baumeister, R. F. (2016). How to make nothing out of something: Analyses of the impact of study sampling and statistical interpretation in misleading metaanalytic conclusions. Frontiers in Psychology, 7, 1639. https:// doi.org/10.3389/fpsyg.2016.01639

Dai, H., Milkman, K. L., Hofmann, D. A., \& Staats, B. R. (2014). The impact of time at work and time off from work on rule compliance: The case of hand hygiene in health care. The Journal of Applied Psychology, 100, 846-862. https://doi.org/ $10.1037 / \mathrm{a} 0038067$

Dang, J. (2016a). Commentary: A multilab preregistered replication of the ego-depletion effect. Frontiers in Psychology, 7, 2-5. https://doi.org/10.3389/fpsyg.2016.01155

Dang, J. (2016b). Testing the role of glucose in self-control: A meta-analysis. Appetite, 107, 222-230. https://doi.org/ 10.1016/j.appet.2016.07.021

Donnellan, M. B., Lucas, R. E., \& Cesario, J. (2015). On the association between loneliness and bathing habits: Nine replications of Bargh and Shalev (2012) study 1. Emotion, 15, 109-119. https://doi.org/10.1037/a0036079

Doyen, S., Klein, O., Pichon, C. L., \& Cleeremans, A. (2012). Behavioral priming: It's all in the mind, but whose mind? PLoS One, 7, e29081. https://doi.org/10.1371/journal.pone.0029081

Duckworth, A. L., \& Kern, M. L. (2011). A meta-analysis of the convergent validity of self-control measures. Journal of Research in Personality, 45, 259-268. https://doi.org/10.1016/ j.jrp.2011.02.004

Evans, D. R., Boggero, I. A., \& Segerstrom, S. C. (2016). The nature of self-regulatory fatigue and "Ego Depletion": Lessons from physical fatigue. Personality and Social Psychology Review, 20, 291-310. https://doi.org/10.1177/1088868315597841

Finley, A. J., Tang, D., \& Schmeichel, B. J. (2019). Sweet nothings: No effects of self-control exertion on blood glucose levels. Social Psychology, 50, 322-331. https://doi.org/10.1027/18649335/a000376
Flore, P. C., Mulder, J., \& Wicherts, J. M. (2019). The influence of gender stereotype threat on mathematics test scores of Dutch high school students: A registered report. Comprehensive Results in Social Psychology, 3, 140-174. https://doi.org/ 10.1080/23743603.2018.1559647

Flore, P. C., \& Wicherts, J. M. (2015). Does stereotype threat influence performance of girls in stereotyped domains? A meta-analysis. Journal of School Psychology, 53, 25-44. https://doi.org/10.1016/J.JSP.2014.10.002

Francis, Z. Z., Milyavskaya, M., Lin, H., \& Inzlicht, M. (2018). Development of a within-subject, repeated-measures ego depletion paradigm: Inconsistent results and future recommendations. Social Psychology, 49, 271-286. https://doi.org/ 10.1027/1864-9335/a000348

Friese, M., \& Frankenbach, J. (in press). P-hacking and publication bias interact to distort meta-analytic effect size estimates. In Psychological Methods.

Friese, M., Frankenbach, J., Job, V., \& Loschelder, D. D. (2017) Does self-control training improve self-control? A metaanalysis. Perspectives on Psychological Science, 12, 10771099. https://doi.org/10.1177/1745691617697076

Friese, M., Loschelder, D. D. D., Gieseler, K., Frankenbach, J., \& Inzlicht, M. (2019). Is ego depletion real? An analysis of arguments. Personality and Social Psychology Review, 23, 107-131. https://doi.org/10.1177/1088868318762183

Furley, P., Kohlhaas, S., Englert, C., Nieuwenhuys, A., \& Bertrams, A. (2019). The expression of ego depletion: Thin slices of nonverbal behavior as cues to momentary self-control capacity. Social Psychology, 50, 305-321. https://doi.org/10.1027/18649335/a000370

Gailliot, M. T., Baumeister, R. F., DeWall, C. N., Maner, J. K. Plant, E. A., Tice, D. M., ... Schmeichel, B. J. (2007). Selfcontrol relies on glucose as a limited energy source: Willpower is more than a metaphor. Journal of Personality and Social Psychology, 92, 325-336. https://doi.org/10.1037/0022-3514. 92.2.325

Ganley, C. M., Mingle, L. A., Ryan, A. M., Ryan, K., Vasilyeva, M., \& Perry, M. (2013). An examination of stereotype threat effects on girls' mathematics performance. Developmental Psychology, 49, 1886-1897. https://doi.org/10.1037/a0031412

Giacomantonio, M., Jordan, J., \& Fennis, B. (2019). Intense selfregulatory effort increases need for conservation and reduces attractiveness of energy-requiring rewards. Social Psychology, 50, 355-369. https://doi.org/10.1027/1864-9335/a000395

Gieseler, K., Loschelder, D. D., \& Friese, M. (2019). What makes for a good theory? How to evaluate a theory using the strength model of self-control as an example. In K. Sassenberg \& M. Vliek (Eds.), Social psychology in action (pp. 3-21). Cham: Springer. https://doi.org/10.1007/978-3-030-13788-5_1

Glerum, J., Loyens, S. M. M., Wijnia, L., \& Rikers, R. M. J. P. (2019). The effects of praise for effort versus praise for intelligence on vocational education students. Educational Psychology, 1-17. https://doi.org/10.1080/01443410.2019.1625306

Goh, J. X., Hall, J. A., \& Rosenthal, R. (2016). Mini meta-analysis of your own studies: Some arguments on why and a primer on how. Social and Personality Psychology Compass, 10, 535-549. https://doi.org/10.1111/spc3.12267

Hagger, M. S., Wood, C., Stiff, C., \& Chatzisarantis, N. L. D. (2010). Ego depletion and the strength model of self-control: A metaanalysis. Psychological Bulletin, 136, 495-525. https://doi.org/ 10.1037/a0019486

Hagger, Martin S., Chatzisarantis, N. L. D., Alberts, H., Anggono, C. O., Batailler, C., Birt, A. R., ... Cannon, T. (2016). A multi-lab pre-registered replication of the ego-depletion effect. Perspectives on Psychological Science, 11, 1227-1234. https://doi.org/ 10.1177/0956797614526415.Data 
Harris, C. R., Coburn, N., Rohrer, D., \& Pashler, H. (2013). Two failures to replicate high-performance-goal priming effects. PLOS One, 8, e72467. https://doi.org/10.1371/journal.pone.0072467

Hockey, G. R. J. (2013). The psychology of fatigue. Cambridge, UK: Cambridge University Press.

Hofmann, W., Baumeister, R. F., Förster, G., \& Vohs, K. D. (2012). Everyday temptations: An experience sampling study of desire, conflict, and self-control. Journal of Personality and Social Psychology, 102, 1318-1335. https://doi.org/10.1037/a0026545

Inzlicht, M., \& Berkman, E.T. (2015). Six questions for the resource model of control (and some answers). Social and Personality Psychology Compass, 9/10, 1-14. https://doi.org/ 10.1111/spc3.12200

Inzlicht, M., Gervais, W. M., \& Berkman, E. T. (2015). Biascorrection techniques alone cannot determine the size of the ego depletion effect (pp. 1-30). Retrieved from https://doi.org/ 10.2139/ssrn.2659409

Inzlicht, M., \& Schmeichel, B. J. (2012). What is ego depletion? Toward a mechanistic revision of the resource model of selfcontrol. Perspectives on Psychological Science, 7, 450-463. https://doi.org/10.1177/1745691612454134

Inzlicht, M., \& Schmeichel, B. J. (2016). Beyond limited resources: Self-control failure as the product of shifting priorities. In Kathleen D. Vohs \& R. F. Baumeister (Eds.), Handbook of selfregulation: Research, theory, and applications (3rd ed., pp. 165181). New York, NY: Guilford Press.

Inzlicht, M., Schmeichel, B. J., \& Macrae, C. N. (2014). Why selfcontrol seems (but may not be) limited. Trends in Cognitive Sciences, 18, 127-133. https://doi.org/10.1016/j.tics.2013.12. 009

Klein, R. A., Vianello, M., Hasselman, F., Adams, B. G., Adams, R. B., Alper, S., .. Nosek, B. A. (2018). Many labs 2: Investigating variation in replicability across samples and settings. Advances in Methods and Practices in Psychological Science, 1 , 443-490. https://doi.org/10.1177/2515245918810225

Kool, W., \& Botvinick, M. (2014). A labor/leisure tradeoff in cognitive control. Journal of Experimental Psychology: General, 143, 131-141. https://doi.org/10.1037/a0031048

Kurzban, R. (2010). Does the brain consume additional glucose during self-control tasks? Evolutionary Psychology, 8, 244-259. https://doi.org/10.1177/147470491000800208

Kurzban, R., Duckworth, A., Kable, J. W., \& Myers, J. (2013). An opportunity cost model of subjective effort and task performance. The Behavioral and Brain Sciences, 36, 661-679. https://doi.org/10.1017/S0140525X12003196

Lewis, M. (2012). Obama's way. Retrieved from https://www.vanityfair.com/news/2012/10/michael-lewis-profile-barackobama

Lin, H., Saunders, B., Friese, M., \& Inzlicht, M. (2019). Strong effort manipulations reduce response caution: A preregistered reinvention of the ego depletion paradigm Unpublished manuscript

Lodder, P., Ong, H. H., Grasman, R. P. P. P., \& Wicherts, J. M. (2019). A comprehensive meta-analysis of money priming. Journal of Experimental Psychology: General, 148, 688-712. https://doi.org/10.1037/xge0000570

Loschelder, D. D., \& Friese, M. (2016). Moderators of the ego depletion effect. In E. R. Hirt, J. J. Clarkson, \& L. Jia (Eds.), Selfregulation and ego control (pp. 21-42). San Diego, CA: Elsevier Academic Press. https://doi.org/10.1016/B978-0-12-8018507.00002-0

Luethi, M. S., Friese, M., Binder, J., Boesiger, P., Luechinger, R., \& Rasch, B. (2016). Motivational incentives lead to a strong increase in lateral prefrontal activity after self-control exertion. Social Cognitive and Affective Neuroscience, 11, 1618-1626. https://doi.org/10.1093/scan/nsw073
Lurquin, J. H., Michaelson, L. E., Barker, J. E., Gustavson, D. E., von Bastian, C. C., Carruth, N. P., \& Miyake, A. (2016). No evidence of the ego-depletion effect across task characteristics and individual differences: A pre-registered study. PLoS One, 11, e0147770. https://doi.org/10.1371/journal.pone.0147770

Lurquin, J. H., \& Miyake, A. (2017). Challenges to ego-depletion research go beyond the replication crisis: A need for tackling the conceptual crisis. Frontiers in Psychology, 8, 568. https:// doi.org/10.3389/fpsyg.2017.00568

Masicampo, E. J., Martin, S. R., \& Anderson, R. A. (2014). Understanding and overcoming self-control depletion. Social and Personality Psychology Compass, 8, 638-649. https://doi.org/ $10.1111 / \mathrm{spc} 3.12139$

Miller, H. C., Pattison, K. F., DeWall, C. N., Rayburn-Reeves, R., \& Zentall, T. R. (2010). Self-control without a "self"? Common self-control processes in humans and dogs. Psychological Science, 21, 534-538. https://doi.org/10.1177/ 0956797610364968

Milyavskaya, M., \& Inzlicht, M. (2017). What's so great about selfcontrol? Examining the importance of effortful self-control and temptation in predicting real-life depletion and goal attainment. Social Psychological and Personality Science, 8, 603-611. https://doi.org/10.1177/1948550616679237

Milyavskaya, M., Inzlicht, M., Johnson, T., \& Larson, M. J. (2018). Reward sensitivity following boredom and cognitive effort: A high-powered neurophysiological investigation. Neuropsychologia, 123, 159-168. https://doi.org/10.1016/j.neuropsychologia. 2018.03.033

Miyake, A., Kost-Smith, L. E., Finkelstein, N. D., Pollock, S. J., Cohen, G. L., \& Ito, T. A. (2010). Reducing the gender achievement gap in college science: A classroom study of values affirmation. Science, 330, 1234-1237. https://doi.org/ 10.1126/science.1195996

Muraven, M., Gagné, M., \& Rosman, H. (2008). Helpful self-control: Autonomy support, vitality, and depletion. Journal of Experimental Social Psychology, 44, 573-585. https://doi.org/ 10.1016/j.jesp.2007.10.008

Muraven, M., \& Slessareva, E. (2003). Mechanisms of self-control failure: Motivation and limited resources. Personality and Social Psychology Bulletin, 29, 894-906. https://doi.org/10.1177/ 0146167203029007008

Muraven, M., Tice, D. M., \& Baumeister, R. F. (1998). Self-control as limited resource: Regulatory depletion patterns. Journal of Personality and Social Psychology, 74, 774-789. https://doi. org/10.1037/0022-3514.74.3.774

Nosek, B. A., \& Lakens, D. (2014). Registered reports: A method to increase the credibility of published results. Social Psychology, 45, 137-141. https://doi.org/10.1027/1864-9335/a000192

O'Donnell, M., Nelson, L. D., Ackermann, E., Aczel, B., Akhtar, A., Aldrovandi, S., \& Zrubka, M. (2018). Registered replication report: Dijksterhuis and van Knippenberg (1998). Perspectives on Psychological Science, 13, 268-294. https://doi.org/ $10.1177 / 1745691618755704$

Open Science Collaboration. (2015). Estimating the reproducibility of psychological science. Science, 349, aac4716-. https://doi. org/10.1126/science.aac4716

Pennington, C. R., Litchfield, D., McLatchie, N., \& Heim, D. (2019). Stereotype threat may not impact women's inhibitory control or mathematical performance: Providing support for the null hypothesis. European Journal of Social Psychology, 49, 717734. https://doi.org/10.1002/ejsp.2540

Persson, E., Barrafrem, K., Meunier, A., \& Tinghög, G. (2019). The effect of decision fatigue on surgeons' clinical decision making. Health Economics, 28, 1194-1203. https://doi.org/10.1002/ hec.3933 
Randles, D., Harlow, I., \& Inzlicht, M. (2017). A pre-registered naturalistic observation of within domain mental fatigue and domain-general depletion of self-control. PLoS One, 12, e0182980. https://doi.org/10.1371/journal.pone.0182980

Richard, F. D., Bond, C. F., \& Stokes-Zoota, J. J. (2003). One hundred years of social psychology quantitatively described. Review of General Psychology, 7, 331-363. https://doi.org/ 10.1037/1089-2680.7.4.331

Saunders, B., Milyavskaya, M., Etz, A., Randles, D., \& Inzlicht, M. (2018). Reported self-control is not meaningfully associated with inhibition-related executive function: A Bayesian analysis. Collabra: Psychology, 4, 39. https://doi.org/10.1525/collabra. 134

Sievertsen, H. H., Gino, F., \& Piovesan, M. (2016). Cognitive fatigue influences students' performance on standardized tests. Proceedings of the National Academy of Sciences of the United States of America, 113, 2621-2624. https://doi.org/10.1073/ pnas.1516947113

Silvestrini, N., Vuignier, E., Matthey, A., \& Piguet, V. (2019). The perception of available resources influences the after-effect of cognitive control on cognitive performance and pain. Social Psychology, 50, 332-344. https://doi.org/10.1027/1864-9335/ a000386

Simmons, J. P., Nelson, L. D., \& Simonsohn, U. (2011). Falsepositive psychology: Undisclosed flexibility in data collection and analysis allows presenting anything as significant. Psychological Science, 22, 1359-1366. https://doi.org/10.1177/ 0956797611417632

Sisk, V. F., Burgoyne, A. P., Sun, J., Butler, J. L., \& Macnamara, B. N. (2018). To what extent and under which circumstances are growth mind-sets important to academic achievement? Two meta-analyses. Psychological Science, 29, 549-571. https://doi.org/10.1177/0956797617739704

Spencer, S. J., Steele, C. M., \& Quinn, D. M. (1999). Stereotype threat and women's math performance. Journal of Experimental Social Psychology, 35, 4-28. https://doi.org/10.1006/ jesp.1998.1373

Steele, C. M., \& Aronson, J. (1995). Stereotype threat and the intellectual test performance of African Americans. Journal of Personality and Social Psychology, 69, 797-811. https://doi. org/10.1037/0022-3514.69.5.797

Vadillo, M. A. (2019). Ego depletion may disappear by 2020. Social Psychology, 50, 282-291. https://doi.org/10.1027/1864-9335/ a000375

Vadillo, M. A., Gold, N., \& Osman, M. (2016). The bitter truth about sugar and willpower: The limited evidential value of the glucose model of ego depletion. Psychological Science, 27, 1207-1214. https://doi.org/10.1177/0956797616654911

Vohs, K. D., Glass, B. D., Maddox, W. T., \& Markman, A. B. (2010). Ego depletion is not just fatigue: Evidence from a total sleep deprivation experiment. Social Psychological and Personality Science, 2, 166-173. https://doi.org/10.1177/1948550610386123

Wagenmakers, E. J., Beek, T., Dijkhoff, L., Gronau, Q. F., Acosta, A., Adams, R. B., ... Zwaan, R. A. (2016). Registered replication report: Strack, Martin, \& Stepper (1988). Perspectives on
Psychological Science, 11, 917-928. https://doi.org/10.1177/ 1745691616674458

Wenzel, M., Lind, M., Rowland, Z., Zahn, D., \& Kubiak, T. (2019). The limits of ego depletion: A crossover study on the robustness of performance deterioration in consecutive tasks. Social Psychology, 50, 292-304. https://doi.org/10.1027/18649335/a000365

Wenzel, M., Rowland, Z., Zahn, D., \& Kubiak, T. (2019). Let there be variance: Individual differences in consecutive self-control in a laboratory setting and daily life. European Journal of Personality, 33, 468-487. https://doi.org/10.1002/per.2208

Westgate, E. C., \& Wilson, T. D. (2018). Boring thoughts and bored minds: The MAC model of boredom and cognitive engagement. Psychological Review, 125, 689-713. https://doi.org/10.1037/ rev0000097

Wilkowski, B. M., Ferguson, E. L., Williamson, L. Z., \& Lappi, S. K. (2018). (How) Does initial self-control undermine later selfcontrol in daily life? Personality and Social Psychology Bulletin, 44, 1315-1329. https://doi.org/10.1177/0146167218766857

Wimmer, M., Dome, L., Hancock, P., \& Wennekers, T. (2019). Is the letter cancellation task a suitable index of ego-depletion? Empirical and conceptual issues. Social Psychology, 50, 345-354. https://doi.org/10.1027/1864-9335/a000393

Xu, X., Demos, K. E., Leahey, T. M., Hart, C. N., Trautvetter, J., Coward, P., ... Wing, R. R. (2014). Failure to replicate depletion of self-control. PLos One, 9, e109950. https://doi.org/10.1371/ journal.pone.0109950

Yeager, D. S., Hanselman, P., Walton, G. M., Murray, J. S. Crosnoe, R., Muller, C., ... Dweck, C. S. (2019). A national experiment reveals where a growth mindset improves achievement. Nature, 573, 364-369. https://doi.org/10.1038/s41586019-1466-y

Zigerell, L. J. (2017). Potential publication bias in the stereotype threat literature: Comment on Nguyen and Ryan (2008). Journal of Applied Psychology, 102, 1159-1168. https://doi.org/ 10.1037/apl0000188

\section{History}

Accepted September 16, 2019

Published online November 5, 2019

\section{Michael Inzlicht}

Department of Psychology

University of Toronto

1265 Military Trail

Toronto, ON M1C 1 A3

Canada

michael.inzlicht@utoronto.ca

\section{Malte Friese}

Department of Psychology

Saarland University

66123 Saarbrücken

Germany

malte.friese@uni-saarland.de 